\title{
Uso do rejeito da dessalinização de água salobra para irrigação da erva-sal (Atriplex nummularia)
}

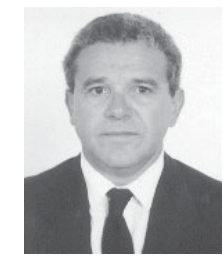

Everaldo R. Porto ${ }^{1}$, Míriam C.C. de Amorim² \& Luis G. de A. Silva Júnior ${ }^{3}$

\begin{abstract}
1 Embrapa Semi-Árido, CEP 56300-970, Petrolina, PE. Fone: (81) 862-1711. E-mail: erporto@cpatsa.embrapa.br (Foto)
${ }^{2}$ Companhia Pernambucana de Saneamento/COMPESA. Petrolina, PE. Fone: (81) 862-3761. E-mail: luizgjr@uol.com.br

${ }^{3}$ Companhia de Desenvolvimento do Vale do São Francisco/CODEVASF. Petrolina, PE. E-mail: luizgjr@uol.com.br
\end{abstract}

Protocolo $061-01 / 06 / 2000$

\begin{abstract}
Resumo: Com o objetivo de se reduzir os impactos causados pela dessalinização de água salobra proveniente do cristalino no trópico semi-árido brasileiro, a erva-sal (Atriplex nummularia) foi cultivada durante um ano, nos campos da Estação Experimental da Embrapa Semi-Árido. As plantas foram irrigadas com rejeito do processo de dessalinização, com concentração salina média de $11,38 \mathrm{dS} \mathrm{m}^{-1}$, e cada uma recebeu $75 \mathrm{~L}$ de água por semana, durante 48 semanas. A salinidade média do perfil de solo, da camada de 0 a $90 \mathrm{~cm}$, era de $0,64 \mathrm{dS} \mathrm{m}^{-1}$ antes de se iniciar a irrigação das plantas; depois da colheita das plantas, a salinidade do mesmo perfil de solo foi de $12,74 \mathrm{dS} \mathrm{m}^{-1}$, enquanto a produtividade da erva-sal foi de $6.537,0 \mathrm{~kg} \mathrm{ha}^{-1}$ de matéria seca, com teor de proteína bruta de $18,40 \%$ nas folhas. A Atriplex apresentou grande potencial de extração de sais do perfil de solo, mas quando as plantas são irrigadas com rejeito de alta concentração salina, a quantidade de sais extraída desse perfil pela planta, é da ordem de 3,93\% do total de sais adicionados ao solo pelas irrigações; isto implica no fato de que, para um manejo de água sustentável, há necessidade de se gerar mais informações sobre as relações de solo e água para a erva-sal, nas condições das zonas áridas do Brasil.
\end{abstract}

Palavras-chave: halófitas, salinidade

\section{The use of the brine from desalting brackish water to irrigate saltbush (Atriplex nummularia)}

\begin{abstract}
Looking forward to reducing environmental impacts resulting from desalting brackish water in the region of the crystalline rocks in the semi-arid tropic of Brazil, saltbush (Atriplex nummularia) was cultivated during one year in an experimental field of Embrapa Semi-Arid. The plants were irrigated with the brine from the desalting plant which presented a salt concentration of $11.38 \mathrm{dS} \mathrm{m} \mathrm{m}^{-1}$. Each plant received $75 \mathrm{~L}$ of water per week, during 48 weeks. The soil salinity, at the depth of $0-90 \mathrm{~cm}$, of the cropped area averaged $0.64 \mathrm{dS} \mathrm{m}^{-1}$ before starting the irrigation process. After the plants were harvested, the soil salinity in the same profile averaged $12.74 \mathrm{dS} \mathrm{m}^{-1}$. The saltbush yield was $6,537.00 \mathrm{~kg} \mathrm{ha}^{-1}$ of dry matter with $18.4 \%$ crude protein in the foliage. The Atriplex presented a great potential for extracting salt from the soil profile. However, when irrigated with concentrated brine, the amount of extracted salt from the soil profile by saltbush plants is in the order of $3.93 \%$ of the total amount of salt added by the irrigations. This implies that, for sustainable water management, it is necessary to generate more information about soil and water relationships for saltbush plants in the arid zones of Brazil.
\end{abstract}

Key words: halophytes, salinity

\section{INTRODUÇÃO}

O uso crescente de equipamentos de dessalinização de água salobra pelo processo de osmose inversa na região semi-árida brasileira, poderá trazer impactos ambientais severos devido ao rejeito produzido, que é composto de água com elevados teores de sais. A depender deste equipamento e da qualidade da água do poço, a quantidade de rejeito gerado será da ordem de 40 a $60 \%$ do total de água salobra que vem do poço. Considerando-se o número de dessalinizadores nesta região, estimado em 400 equipamentos, grande volume de rejeito está sendo gerado no semi-árido brasileiro, e quase na totalidade dos casos, o rejeito não vem recebendo nenhum tratamento, mas está sendo despejado no solo, propiciando alto acúmulo de sais nas camadas superficiais do terreno. A deposição deste rejeito poderá trazer, em curto espaço de tempo, sérios problemas para as comunidades que se beneficiam desta tecnologia, como mostram os dados gerados por Porto et al. (1997). Em geral, nos 
países desenvolvidos o rejeito é transportado para os oceanos ou injetados em poços de grande profundidade; todavia, outras alternativas estão sendo estudadas, como: bacias de evaporação; redução de volume do rejeito por plantas aquáticas; bacias de percolação e irrigação de plantas halófitas (Boegli \& Thullen,1996).

Halófitas são plantas com habilidade de suportar não apenas altos níveis de salinidade do complexo solo-água mas, também, de acumular significativas quantidades de sais em seus tecidos. Dentre as halófitas, a erva-sal é uma das mais importantes.

Erva-sal é o nome vulgar dado, no Brasil, às plantas do gênero Atriplex, pertence à família Chenopodiacea, a qual conta com mais de 400 espécies distribuídas em diversas regiões áridas e semi-áridas do mundo (FAO, 1996). Dentre as espécies da família Chenopodiacea, aproximadamente $15 \%$ interessam à produção animal, sendo a Atriplex nummularia uma das mais importantes, como forrageira. A Atriplex nummularia foi introduzida no Nordeste brasileiro através da Inspetoria Federal de Obras Contra as Secas, na década de 30 (Obras..., 1938).

Por se originar de regiões áridas, o gênero Atriplex vem-se destacando, há algumas décadas, principalmente por conseguir produzir e manter uma abundante fitomassa, mesmo em ambientes de alta aridez e salinidade, adaptando-se muito bem a regiões com precipitação ao redor de 100 a $250 \mathrm{~mm} \mathrm{ano}^{-1}$. Mais recentemente, as plantas de Atriplex têm-se destacado na perspectiva de se desenvolverem espécies apropriadas para irrigação com água do mar. Segundo Glenn et al. (1995) 50 milhões de hectares podem ser trazidos para a produção agrícola, através da irrigação com água do mar, utilizando-se espécies halófitas; todavia, para as condições do semi-árido brasileiro não existem informações do cultivo dessas espécies irrigadas com água de alta salinidade.

Com o objetivo de se avaliar técnicas para redução dos impactos ambientais causados pelo rejeito, este trabalho apresenta os resultados do comportamento da erva-sal irrigada com o rejeito da dessalinização de água, por osmose inversa.

\section{MATERIAL E MÉTODOS}

A forrageira halófita selecionada para este trabalho foi a erva-sal (Atriplex nummularia). No experimento, as mudas foram plantadas em espaçamento de $3 \times 3 \mathrm{~m}$, em delineamento experimental de blocos ao acaso, contendo 16 plantas em cada parcela. Em cada bloco continham quatro parcelas. Os blocos foram repetidos três vezes. A área total do experimento foi de $1728 \mathrm{~m}^{2}$. A irrigação foi por sulco e a quantidade de água aplicada foi de $300 \mathrm{~L}$ de rejeito por sulco de $12 \mathrm{~m}$, perfazendo o total de 75 L de água por planta por semana. Efetuou-se a aplicação da água uma vez por semana e a salinidade média do rejeito utilizado na irrigação foi de $11,38 \mathrm{dS} \mathrm{m}^{-1}$ enquanto as mudas foram plantadas em 27/02/98 e colhidas em 12/03/99, originárias de uma única planta por estaquia. Durante este período efetuaram-se 48 irrigações. $\mathrm{O}$ monitoramento da salinidade foi realizado no solo, a intervalos de $30 \mathrm{~cm}$, indo da camada superficial até a profundidade de $90 \mathrm{~cm}$. Amostras de solo foram retiradas antes do plantio e após a colheita da erva-sal. No solo, a determinação dos totais de sais foi efetuada através da medição da condutividade elétrica da solução do solo; também foram feitas estimativas dos quantitativos de sais acumulados nos tecidos da planta, através da determinação de cinzas totais. Efetuou-se a colheita com a retirada de todo o material da parte aérea da planta com altura superior a $50 \mathrm{~cm}$; por outro lado, o material colhido de cada planta foi classificado como lenha, caule, ramos e folhas; como caule, foi considerado todo o material lenhoso com diâmetro máximo medindo cerca de $8,0 \mathrm{~mm}$ e, como lenha, todo material lenhoso superior a este; por fim, foi denominado material forrageiro o conjunto de caule, ramos e folhas.

\section{RESULTADOS E DISCUSSÃO}

Na Tabela 1 são apresentados os resultados das análises químicas do solo, da área usada pelo cultivo, antes e depois de ter recebido as irrigações, nas profundidades de 0-30, 30-60 e $60-90 \mathrm{~cm}$. As salinidades médias do perfil foram de $0,64 \mathrm{e}$ $12,74 \mathrm{dS} \mathrm{m}^{-1}$ antes e depois do ciclo do cultivo, respectivamente.

A partir dos dados de acompanhamento da salinidade da água do rejeito, usada para irrigar a erva-sal, foi produzido o gráfico da Figura 1. Durante o período de cultivo, a salinidade média menor ocorreu no mês de junho, com valor de 9,46 dS m-1, e a maior, no mês de fevereiro, com $12,70 \mathrm{dS} \mathrm{m}^{-1}$.

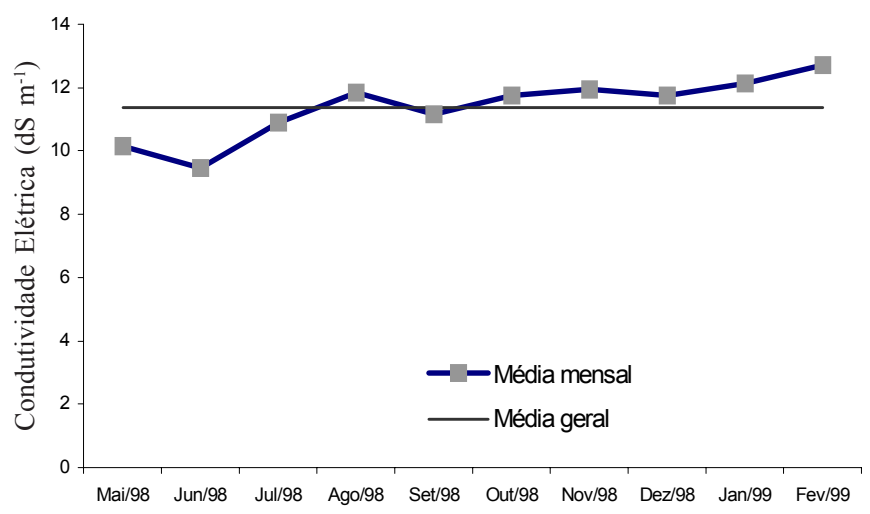

Figura 1. Comportamento da salinidade da água do rejeito da dessalinização

Em geral, a erva-sal, como outras espécies halófitas, apresenta boa performance no desenvolvimento vegetativo, mesmo em ambientes marginais. A Figura 2 demonstra o crescimento da planta cultivada com irrigação, nas condições do semi-árido brasileiro. A altura média das plantas, após um ano, foi de 2,20 m e a distância alcançada pelos ramos prostrados no solo, de 1,85 m.

Tabela 1. Resultados das análises de solo, comparando-se os dados do solo antes e depois de irrigado

\begin{tabular}{|c|c|c|c|c|c|c|}
\hline \multirow{3}{*}{ Composição } & \multicolumn{6}{|c|}{ Profundidade do Solo $(\mathrm{cm})$} \\
\hline & \multicolumn{3}{|c|}{ Antes da Irrigação } & \multicolumn{3}{|c|}{ Após a Irrigação } \\
\hline & $0-30$ & $30-60$ & $60-90$ & $0-30$ & $30-60$ & $60-90$ \\
\hline Umidade de Saturação & 26,00 & 25,36 & 33,25 & 26,55 & 28,81 & 34,40 \\
\hline $\mathrm{pH}$ & 6,70 & 6,60 & 5,90 & 6,70 & 6,20 & 5,90 \\
\hline $\mathrm{CE} 25^{\circ}\left(\mathrm{dS} \mathrm{m} \mathrm{m}^{-1}\right)$ & 0,41 & 0,80 & 0,72 & 13,00 & 12,61 & 12,62 \\
\hline
\end{tabular}




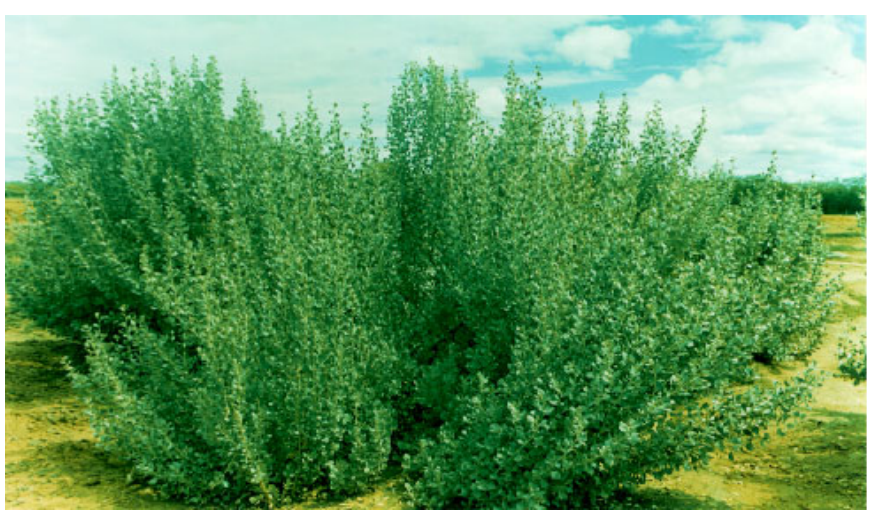

Figura 2. Atriplex nummularia irrigada com o rejeito da dessalinização de água salobra, com um ano de idade

Na Tabela 2 tem-se o peso total em matéria fresca de cada uma das parcelas colhidas de Atriplex nummularia, após um ano de idade. Por sua vez, cada parcela é constituída por 16 plantas, produzindo uma média geral de $23,4 \mathrm{~kg}$ de material por planta. $\mathrm{O}$ total de produção de todo o conjunto de plantas da área é de $4.504,0 \mathrm{~kg}$, alcançando a produtividade de $26.064,0 \mathrm{~kg} \mathrm{ha}^{-1}$ colhido, considerando-se a densidade de plantio de 1.111 plantas ha $^{-1}$.

Tabela 2. Produção de matéria fresca colhida de Atriplex nummularia no $1^{\circ}$ corte

\begin{tabular}{|c|c|c|c|c|}
\hline \multicolumn{5}{|c|}{ Peso Total Colhido por Parcela de 16 Plantas (kg) } \\
\hline Repetição & Bloco 1 & Bloco 2 & Bloco 3 & Média \\
\hline 1 & 328,5 & 404,0 & 416,5 & \\
\hline 2 & 391,0 & 410,0 & 296,0 & \\
\hline 3 & 344,5 & 343,0 & 392,5 & \\
\hline 4 & 368,5 & 366,0 & 441,5 & \\
\hline Média/Blo & 358,1 & 381,2 & 386,6 & 375,3 \\
\hline Média/Planta & 22,4 & 23,8 & 24,2 & 23,4 \\
\hline & Produ & $\begin{array}{l}\text { Produç } \\
\text { idade Es }\end{array}$ & $\begin{array}{l}\text { otal Obti } \\
\text { da (kg ha }\end{array}$ & $\begin{array}{r}4.504,0 \\
26.064,0\end{array}$ \\
\hline
\end{tabular}

Na Tabela 3 são apresentados os detalhes da produção para as diferentes partes da planta. É importante atentar-se para o que está sendo chamado de ramo e caule. Ramo é todo material tenro que suporta as folhas, enquanto caule é todo o material lenhoso com diâmetro igual ou inferior à espessura de um lápis comum. Por outro lado, o restante do material lenhoso colhido é considerado lenha. De acordo com esta tabela, o material predominante é a folhagem, como pode ser visto na coluna que demonstra a proporção em relação ao total da planta.

A erva-sal é considerada planta forrageira apropriada ao ambiente semi-árido (FAO, 1996). Na Tabela 4 são indicados os resultados das estimativas, por hectare, dos totais e de partes da planta, tanto na forma de matéria fresca como os correspondentes em matéria seca.
Tabela 3. Total de matéria fresca e percentual produzido por parte das plantas

\begin{tabular}{lcc} 
Parte da & Produção Matéria Fresca \\
Planta & $\begin{array}{c}\text { Proporção em Relação ao } \\
\text { Total da Planta (\%) }\end{array}$ \\
\hline Total & $4.504,0$ & 100,0 \\
Folha & $2.557,0$ & 56,7 \\
Ramo & 552,0 & 12,3 \\
Caule & 571,0 & 12,7 \\
Lenha & 824,0 & 18,3 \\
\hline
\end{tabular}

A literatura demonstra variabilidade entre 2,9 a 10,0 $\mathrm{tha}^{-1} \mathrm{de}$ rendimento da Atriplex nummularia, principalmente em resposta à qualidade do ambiente de cultivo (O'Leary, 1986). Também, essas diferenças são influenciadas sob o ponto de vista de manejo, condução das práticas culturais e de colheita, como espaçamento, lâmina d'água, altura e periodicidade do corte.

A Tabela 5 apresenta as estimativas de sais retirados do solo pela erva-sal, através dos dados de cinza encontrados nos tecidos das diversas partes da planta. De acordo com os dados apresentados, as plantas retiraram $1.145,00 \mathrm{~kg} \mathrm{de} \mathrm{sal} \mathrm{ha-1}$ ano.

Tabela 5. Estimativa do total de sal (cinzas) retirado do solo pela erva-sal $\left(\mathrm{kg} \mathrm{ha}^{-1}\right)$

\begin{tabular}{lrrrrrr}
\hline & & \multicolumn{5}{c}{ Parte da Planta } \\
\cline { 2 - 7 } Composição & & & \multicolumn{4}{c}{ Material Forrageiro } \\
\cline { 2 - 7 } & Total & Lenha & Folha & Ramo & Caule & Total \\
\hline Cinza & $1.145,00$ & 92,00 & 864,00 & 120,00 & 69,00 & $1.053,00$ \\
\hline
\end{tabular}

Como se pode observar na Tabela 5, o maior acúmulo de sais ocorre na folha, por conta da formação de vesículas especiais, constituída por pequenos bolsos na superfície dos tecidos da folhagem. De acordo com Sharma (1982) essas vesículas são formadas por células vacuoladas, com diâmetro que variam de 100 a $200 \mu$, muito ricas em sais, que se constituem em elementos reguladores das concentrações eletrolíticas da folha servindo, particularmente, para a acumulação dos excedentes de $\mathrm{NaCl}$.

Em razão da capacidade de assimilar sais que a erva-sal possui, os pesquisadores têm-se motivado para utilizá-la como recuperadora de áreas degradadas pela salinização do solo. Esta retirada de sais, os quais são incorporados aos tecidos da planta, varia de acordo com a idade e as condições oferecidas no período de cultivo.

Considerando-se a condutividade elétrica média anual do rejeito apresentado na Figura 1 e a quantidade de água aplicada durante o ciclo de cultivo da Atriplex, estima-se que foi adicionado ao solo, para uma densidade de 1.111 plantas ha $^{-1}, \mathrm{o}$ total de 29.117,00 kg ha-1 de sais. De acordo com a Tabela 5, a estimativa da quantidade de sal retirada pelo cultivo da erva-sal é de $1.145,00 \mathrm{~kg} \mathrm{ha}^{-1}$, para uma água de irrigação com salinidade equivalente a $11,38 \mathrm{dS} \mathrm{m}^{-1}$ ou $7,28 \mathrm{~g} \mathrm{~L}^{-1}$; portanto, para os tipos

Tabela 4. Estimativa dos rendimentos do total e de partes da planta da erva-sal $\left(\mathrm{kg} \mathrm{ha}^{-1}\right)$

\begin{tabular}{lrrrrrr}
\hline & \multicolumn{5}{c}{ Parte Colhida } \\
\cline { 4 - 7 } Composição & & \multicolumn{5}{c}{ Material Forrageiro } \\
\cline { 4 - 7 } & Total & Lenha & Folha & Ramo & Caule & Total \\
\hline Matéria fresca & $26.064,00$ & $4.768,00$ & $14.797,00$ & $3.194,00$ & $3.305,00$ & $21.296,00$ \\
Matéria seca & $9.436,00$ & $2.899,00$ & $3.425,00$ & $1.402,00$ & $1.710,00$ & $6.537,00$ \\
\% MS (pré-secagem) & 36,20 & 60,80 & 23,15 & 43,89 & 51,75 & 30,70 \\
\hline
\end{tabular}


de água e manejo usados, a retirada de sais pela erva-sal corresponde a 3,93\% do total de sais aplicados pela água do rejeito; todavia, à luz das informações ora disponíveis sobre o uso desta planta, nas condições do semi-árido brasileiro, como estratégia de uso do rejeito da dessalinização de água por osmose inversa, há necessidade de mais estudos, objetivando-se definir melhor as implicações nas relações solo-água-planta, quando da utilização de rejeito de alta concentração salina.

\section{CONCLUSÕES}

1. A erva-sal consegue retirar grande quantidade de sais do solo, quando comparada com plantas não halófitas, apesar da remoção não ser tão significativa, quando comparada ao quantitativo de sais adicionados ao solo através da irrigação com água de alta salinidade.

2. De acordo com os resultados preliminares apresentados, pode-se considerar a Atriplex nummularia, ou erva-sal, como cultivo que suporta ambientes de alta salinidade, podendo mesmo ser tida como de grande habilidade na remoção de sais encontrados no solo de áreas salinizadas.

\section{LITERATURA CITADA}

Boegli, W.J.; Thullen, J.S. Eastern municipal water district to treatment/saline vegetated wetlands pilot study: Final report. Denver, Colorado: U.S. Department of the Interior, Bureau of Reclamation, 1996. 116p. il. Water Treatment Technology. Program Report, 16.
FAO (Roma, Itália). Estudios de case de espécies vegetales para zonas áridas y semiáridas de Chile y México. Santiago: Oficina regional de la FAO para América Latina y el Caribe, 1996. 143p. il. FAO. Oficina Regional para América Latina y el Caribe, Zonas Áridas y Semiáridas, 10

Glenn, E. Hicks, N.; Riley, J.; Swingle, S. Seawater irrigation of halophytes for animal feed. In: Choukr-Allah, R.; Malcolm, C. V.; Hamdy, A. Halophytes and biosaline agriculture. New York: Marcel Dekker, 1995. cap.11, p.221-236.

Obras contra as secas: Objetivos, programas, ação da inspetoria, resultados. Boletim da Inspetoria Federal de Obras Contra as Secas, Rio de Janeiro, v.10, n.2, p.157-197, 1938.

O'Leary, J.W. A critical analysis of the use of Atriplex species as crop plant for irrigation with highly saline water. In: Ahmad, R.; San Pietro, A. (eds). Prospects for biosaline research. Karachi: Karachi University, 1986. p.416-432.

Porto, E.R.; Amorim, M.C.C. de; Araújo, O.J.; Silva Júnior, L.G.A.; Aproveitamento dos rejeitos da dessalinização. In: Simpósio sobre Captação de Água de Chuva no Semi-Árido Brasileiro, 1,1997, Petrolina, PE. A captação de água de chuva: base para viabilização do semi-árido brasileiro Anais. Petrolina, PE: Embrapa Semi-Árido/IRPAA/IRCSA, 1999. p.51-57.

Sharma, M.L. Aspects of salinity and water relations of Australian Chenopods. In: Sen, D.N.; Rajpurohit, K.S. (eds) Contributions to the ecology of halophytes. Hague: W. Junk, 1982. cap. 4, p.155-175. Tasks for Vegetation Science, 2 